Utah State University

DigitalCommons@USU

Spark - Empower Teaching Scholarship

Collection

Research Centers

$11-6-2014$

\title{
Why Didn't I Think of That? A Classroom Exercise for Developing Entrepreneurial Thinking
}

Daniel Holland

Utah State University, daniel.holland@usu.edu

Follow this and additional works at: https://digitalcommons.usu.edu/et_schol

Part of the Education Commons

\section{Recommended Citation}

Holland, D. (2014, November 5). Why didn't i think of that? a classroom exercise for developing entrepreneurial thinking. Entrepreneurship \& Innovation Exchange. Retrieved September 5, 2020, from https://eiexchange.com/content/32-why-didnt-i-think-of-that-a-classroom-exercise-f

This Article is brought to you for free and open access by the Research Centers at DigitalCommons@USU. It has been accepted for inclusion in Spark - Empower Teaching Scholarship Collection by an authorized administrator of DigitalCommons@USU. For more information, please contact digitalcommons@usu.edu.

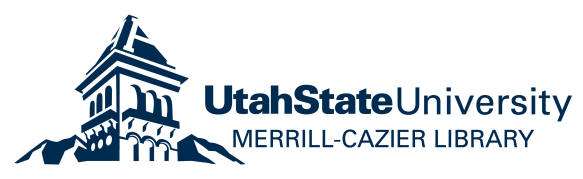




\title{
Why Didn't I Think of That? A Classroom Exercise for Developing Entrepreneurial Thinking
}

\author{
Dan Holland (Utah State University)
}

KEYWORDS: Innovation, Teaching Methods.

Entrepreneurs tend to think differently, juggling different thinking styles more easily than others. They are comfortable with both linear and non-linear thinking, and both causal and effectual logic. In order to help students develop diverse entrepreneurial thinking skills, teachers must employ unique educational strategies. This article provides educators with an engaging openmarket trading card activity that was created to help students identify and overcome barriers to entrepreneurial thinking. Designed for strategy and entrepreneurship classes at the undergraduate and graduate level, this activity challenges students' mental models and sets the stage for a fruitful discussion about entrepreneurial thinking.

As individuals try to make sense of a complex environment, they use mental models that are developed from past experiences, attitudes, and cognitions to draw quick conclusions about the stimuli surrounding them (Holtom, Gagné, \& Tinsley, 2010). Using these mental models is much more efficient than taking the time to analyze every sight, sound, smell, touch and taste that occurs during daily activity. The downside to using static mental models is that they can often stunt creativity and limit options (Johansson, 2006). This can be detrimental to entrepreneurship, because creating innovative new opportunities is often a numbers game, requiring an explosion of ideas that challenge established ways of thinking (Terwiesch \& Ulrich, 2009). Hence, entrepreneurship educators must help students develop adaptive mental models that spur creativity and innovation. This classroom exercise uses a simple learning process that challenges students' existing mental models and introduces alternative ways of thinking, so that they can make a conscious effort to think differently and more creatively in the future. (Brock, 2010).

To download the trading cards for the students, click on "Classroom Exercise," above.

\section{Entrepreneurial Thinking}

Thinking style is defined as "one's preferred manner of using mental abilities to govern daily activities, including understanding and solving problems and challenges" (Vance et al., 2007, 168). Successful entrepreneurs can balance both linear thinking (encompassing rational, logical, and analytical tendencies) and nonlinear thinking (consisting of intuitive, insightful, and creative thought) (Groves et al., 2008; Vance et al., 2007). Entrepreneurs are also more likely to use heuristics to simplify and speed up information processing, which can be particularly beneficial in dynamic entrepreneurial settings, but may also lead to errors in perception (Alvarez \& Busenitz, 2001). Sometimes entrepreneurs take a causal cognitive approach to creating a new venture, which is often taught in business schools-i.e. discover an idea, create a business plan, gather resources, create a team, develop a product or service, and sell the product or service (Chandler et al., 2011). However, many times expert entrepreneurs think more clearly by considering the resources available to start down a path, but allowing the end goal to emerge over time after experimentation and feedback (Sarasvathy, 2001). Such an approach allows for greater flexibility in responding to market needs and promotes "out of the box" thinking. To summarize, research has shown that successful entrepreneurs generally rely on a variety of thinking styles to develop and implement innovative solutions. This means that management educators should develop methods that challenge students to be aware of their natural thinking styles and encourage them to adopt alternative ways of thinking (Goel et al., 2010).

\section{Trading Card Activity}

Entrepreneurial thinking can be developed through effective training and practice. This specific activity provides such practice while implementing all of the important elements of a game, including competition 
and time pressure (Neck \& Greene, 2011; Chang, 2008). Through the use of trading cards, students are given the chance to participate in an open-market experience which requires them to develop, implement and adapt strategies for success. During the postactivity discussion, the instructor has the opportunity to help the students analyze thinking strategies and recognize missed opportunities to use more entrepreneurial thinking. Below are the important elements of the activity.

Reading Assignment. To set the stage for the learning activity, we recommend that the students read an article or two about entrepreneurial thinking before the class. We often use "What makes entrepreneurs entrepreneurial?" by Sarasvathy (2004), among others.

Creating Teams. This activity involves teams of students competing to maximize the value of their holdings. Teams should consist of 2 to 4 students. The exercise is most effective with 8 to 12 teams.

Preparing the Room. This activity requires students to discuss and strategize with team members first, and then to move freely about the room during the open market. In order to improve the effectiveness of the strategy sessions during the activity, instructors should arrange the classroom so that team members can sit together. If possible, it is helpful to arrange desks or tables to provide an open area that allows students to move around during trading sessions. This activity involves several timed sessions of strategizing and trading. In order to keep students aware of the time, it is helpful to project a countdown clock on the wall of the classroom.

Preparing the Trading Cards. Trading cards should be prepared before the class period begins. These cards should include a picture, the name of the person in the picture, and the year of the card. Additionally, a dollarvalue must be assigned to each card. A sample of cards is found in appendix I (please contact the first author for a complete set). A spreadsheet displaying a full set of names, years and dollar-values is also included in appendix II. In total, there should be 10 names/pictures, spread across a span of 10 years (the same 10-year span should be used for each character on the cards). The full set of cards should include at least one complete set of each person and each year (100 cards) plus a number of extra cards. These extra cards may be duplicates of randomly selected cards, or they may be a duplicate set of a person or year. Either way, it is important to begin the activity with more cards than will be passed out to teams. For example, if nine teams receive 12 cards each, 108 cards will be taken by teams. In this case, instructors should prepare more than 108 cards. These extra cards will be used by the instructor during the activity, which will be explained in greater detail below. Cards should be printed, cut out, and ready to pass out before the activity begins.

Explaining the Activity to Students. To begin, instructors should explain the overall goal of the activity; the simple goal is to "maximize the value of your holdings." Instructors should explain that each team, or "company," will randomly select 12 cards (this number can be adjusted based on the number of teams and cards), and that each card has an assigned value. The instructor should provide each team with a copy of a spreadsheet similar to that displayed in appendix II. While showing the document listing the value of each card, instructors should also explain that if teams complete a full set of cards (which can be achieved by collecting all cards of a particular year or person), the set will have a higher value than the sum of the individual cards' values. Instructors should inform the students, without undue emphasis, the total number of teams and the number of cards each team will receive. Attentive students may observe that there may be "extra" cards that are not distributed, which will be important during the activity. The instructions are intentionally basic and minimal. An impactful part of this exercise is the fact that the students will automatically mentally develop and follow additional unstated "rules" for the competition. It is a profound example of how people often fall prey to assumptions and restrict possibilities.

Instructors will further explain that teams will have the opportunity to participate in a market setting with other teams in order to increase and maximize the value of their holdings. A basic outline of the schedule for the class period should be presented as shown in Table 1.

\begin{tabular}{|l|l|l|}
\hline Table 1: Session Schedule for Activity \\
\hline Session & Time & Purpose \\
\hline Strategy Session \#1 & 8 minutes & Teams develop initial strategy, may negotiate, but no trading. \\
\hline Open Market Session \#1 & 8 minutes & Teams attempt to increase the value of their holdings. \\
\hline Strategy Session \#2 & 5 minutes & Tearns revise strategy, may negotiate, but no trading. \\
\hline Open Market Session \#2 & 5 minutes & Teams attempt to increase the value of their holdings. \\
\hline Strategy Session \#3 & 3 minutes & Tearns revise strategy, may negotiate, but no trading. \\
\hline Open Market Session \#3 & 3 minutes & Teams attempt to increase the value of their holdings. \\
\hline
\end{tabular}

Instructors should emphasize that no cards can be 
traded, given away, exchanged, or in any way change ownership during the strategy sessions. Students may ask if they are allowed to converse with other teams during the strategy session, which instructors should allow. They may discuss strategy, negotiate deals, or gather data but they may not carry out a trade.

Lastly, instructors should explain the point system for the activity. We typically make this activity worth 10 points. The team with the most accumulated value receives 10 points. The second and third place teams receive 9 points, several teams receive 8 , and so forth. This grading structure is meant to incentivize students to take the activity seriously. The number of points possible should be enough for students to feel a little pressure and the potential pain of failure but few enough that it will not decimate their overall course grade.

Leading the Activity. After explaining each aspect of the activity, instructors should allow each team to randomly select their cards. The best way to do this is to have all cards on a table (face-down to keep the selection process random), and allow each team to select the designated number of cards. Once all teams have drawn their cards, the remaining cards should be collected.

Throughout the activity, instructors should act as a unique resource provider - of the extra cards and/or information. Attentive students may realize that there are cards that have not been distributed to teams or that there are duplicate cards. These students may inquire about these surplus cards. We recommend that you wait for such inquiries and reward inquisitive students with information or cards. It is up to the instructor to determine how forthcoming and generous with information and cards that he or she would like to be.

Instructors should begin the first strategy session. Instructors may want to walk around the class and observe the various strategies the teams are developing. The three most common strategies are 1) seek to complete a set based on a year, 2) seek to complete a set based on a person, and 3) engage in uptrading by trading low-value cards for higher-value cards. Instructors should feel free to prod discussions through leading questions such as, "will your strategy still work if other teams' strategies are to....?"

An important element of this activity is that the only stated rule is that students cannot exchange cards during the strategy sessions. However, this lack of rules does not need to be blatantly emphasized to the class. It is beneficial for students to consider the context and need to ask clarifying questions such as, "may we talk to other teams during the strategy sessions?," or, "can we trade cards with you?" Due to a lack of set rules, "probably" or "I think so" are often appropriate responses to these questions. The goal is to force students to be entrepreneurial in proactively seeking out resources, such as information or additional cards, in order to be rewarded. They should also be expected to take some risks without certain knowledge of the outcomes of their actions.

At the end of the first strategy session, instructors will announce that the market is now open to trade cards, and reset the timer for 8 minutes. Often, teams will have spent time during their strategy session discussing trades with other teams, so initial trades will happen quickly. However, with a lack of full information in the market, teams will soon find that their strategies may be hindered by the efforts of other teams. For example, a team working to complete a set based on a person and a team trying to complete a set based on a year will both need the same card, but (in most cases) only one team can have it. Consequently, the team who possesses this card may quickly see the value in the rarity of their card which will drive up the asking price. Once deals like this begin, the chaos and strategy of the activity is amplified dramatically.

Also, it is possible that one or two teams will seek out "creative" collaborative solutions. When doing so, they often ask the instructor for permission. While such creativity and risk-taking should be rewarded if implemented, we recommend that during the activity you allow for doubt and risk to remain by providing somewhat vague answers. In other words, if a team asks if they can partner with another team, you might respond with "that may work, but..." or "I don't know, can you really trust them?"

It is recommended that the instructor(s) take a low profile approach during the open market sessions. It is not uncommon for students to ignore the instructor and fail to seek information or even notice that the instructor has extra cards. If a student does approach the teacher, he or she should reward groups that are direct, persistent, and strategic with the requested information or cards. Instructors need not be trading partners, although that is also reasonable, but may choose to be 
resource providers and invest in those teams that have a clear strategy that will benefit from the resources offered.

At the end of the 8-minute trading session, instructors will announce the closure of the market and remind students that during the next 5-minute strategy session, no exchanges can be made. Again, during this time instructors should feel free to visit groups, listen in on their strategizing, and join the discussion as appropriate. Teams often change strategies based on the success or failure of their previous strategy.

Once the 5 minutes has expired, instructors will announce the re-opening of the market for 5 minutes. At the end of the second trading session, instructors will alert the class that they have one final 3-minute strategy session followed by a 3-minute market session. This is the last opportunity for teams to fulfill the goal of the activity, so this session will often be somewhat frantic. At the end of the final session, instructors will announce the close of the market. Often final negotiations are taking place right up to the closing bell and some teams will be tempted to make trades after the close. Instructors should diligently enforce the closed-market rule and require the teams to return to their tables. Each team should tabulate the total value of their holdings. Once scores have been tabulated by individual teams, it is suggested that you assign a student from another team to audit the calculation of the score. Finally, instructors should ask each team to submit a tally of their score to determine the ranking of the teams.

\section{Post-activity Discussion}

After the scores have been calculated and the rankings have been determined, the most important part of this exercise is the post-activity discussion. This is an excellent opportunity to use the students' experiences to discuss linear vs. non-linear thinking; causal vs. effectual thinking; how assumptions and associative barriers stunt creative solutions; the importance of seeking information and other resources; the influence of location and networks; and intended, emergent, and realized strategies. Discussions may include highlights from the pre-activity readings, proceedings of the activity, and additional examples from everyday life. The goal should be to produce a reflective learning environment for the students. "Reflective learning is a process by which the individuals compare the newly gained knowledge with their past understanding in order to derive inferences and gain a deeper appreciation of what has been learned." (Chang, 2008: 153)

The instructor should be prepared to ask a series of questions that challenge the way that the students approached the activity (see Table 2). The post-activity discussion often challenges students' mental models. They come to a realization that they frequently limit their options by placing perceived barriers in their way. Their vast experience of playing games in the past often leads them into following unwritten and unsaid rules. Most often, students fall in line with one of the basic strategies previously mentioned and don't consider other options. For example, they do not consider merging with a group because you just don't do that when you are competing in a game (e.g. Monopoly or Pit). These barriers to creative thinking should be challenged with an analysis of why they may have failed to be creative.

Many principles from the discussion can be easily applied to entrepreneurship. The discussion can be enhanced with real entrepreneurial examples of individuals who challenged assumptions, "broke the rules" or changed the way the game was played. Furthermore, it is likely to produce constructive discussions about emergent strategy, strategic fit, seeking information and other resources, among other things.

\begin{tabular}{|c|c|}
\hline Questions & Discussion Points \\
\hline $\begin{array}{l}\text { What strategy did you employ? How did you determine } \\
\text { that strategy? }\end{array}$ & \begin{tabular}{|l|} 
Causal vs. Effectual approach \\
\end{tabular} \\
\hline $\begin{array}{l}\text { Did you adapt your strategy during the game? What } \\
\text { feedback from the market prompted the change? }\end{array}$ & \begin{tabular}{|l} 
Mintzberg's emergent strategy \\
\end{tabular} \\
\hline $\begin{array}{l}\text { Did you take any risks? Why or why not? What was the } \\
\text { true motivation driving your choices? }\end{array}$ & Risk-taking: Motivation; Fear of failure \\
\hline $\begin{array}{l}\text { Did you consider any strategies other than collecting a } \\
\text { year set, collecting a person set, or collecting high value } \\
\text { cards? If not, why? What restrictions did you place on } \\
\text { yourself that may have prevented you from being more } \\
\text { creative? }\end{array}$ & $\begin{array}{l}\text { Satisficing, Associative barriers that stunt creativity - } \\
\text { the students can often see rules or restrictions that they } \\
\text { placed on themselves due to experiences or perceptions } \\
\text { that they have developed over the years. }\end{array}$ \\
\hline $\begin{array}{l}\text { Did you consider mergers, alliances, trading something } \\
\text { other than cards (e.g. money, candy), increasing the } \\
\text { value of your holdings by chipping in your own money } \\
\text { or assets, offering a service (e.g. mas sages) in exchange } \\
\text { for cards, etc. }\end{array}$ & $\begin{array}{l}\text { These questions generally produce some angst among } \\
\text { the students. They often kick themselves for not think- } \\
\text { ing outside the box. This is a great opportunity to con- } \\
\text { front their existing mental models and challenge them to } \\
\text { consider new mental models. }\end{array}$ \\
\hline $\begin{array}{l}\text { Did you seek out information from the teacher? Did you } \\
\text { strive to gather data (c.g. number of cards, number of } \\
\text { teams, competitors' strategies, duplicate cards, etc.) } \\
\text { before deternining a strategy? }\end{array}$ & $\begin{array}{l}\text { The importance of analy zing the environment and de- } \\
\text { veloping a strategy that is a good fit. }\end{array}$ \\
\hline
\end{tabular}

\section{Assessment of Effectiveness}

This activity has been successfully implemented numerous times in undergraduate entrepreneurship classes and MBA strategy classes. In several recent classes, students were asked to participate in a short learning assessment after the activity was complete. Students were asked to reflect on their feelings about the learning activity (What did you like or dislike most about this learning activity?). Next, they were asked to make conclusions or insightful generalizations that resulted from the activity (From this experience, what 
principle(s) did you learn?). The students were also asked whether they planned to experiment with what they learned (Based on the learning outcomes of this activity, what are the items, if any, that you would most like to practice?). Finally, they were asked whether they would recommend the exercise for future classes and if they have any suggestions for improvement. These assessments were voluntary, and 104 (49 graduate and 55 undergraduate) out of a possible 138 , or $75.4 \%$, students participated.

One demonstration of the activity's success in teaching the desired style of thinking is that over $52 \%$ of students, without prompting, specifically mentioned something related to "out-of-the-box thinking" when describing what they learned from the activity. One student said, "I think the biggest thing I took away from this exercise would be to think 'outside the box'. Don't assume the rules or guidelines of the game. Expand your strategies to try and reach the best results." Another stated, "I liked that it was an activity that made you think outside of the box. Most students, including myself, didn't realize our full potential of what we could have done until the end. The way it was all tied together, about how we place limitations on ourselves because of societal norms, really stood out to me."

Next, there was evidence that the students experienced a disorienting cognitive dilemma that prompted a desire to change -- an important step in transformative learning (Mezirow, 1994). Over 56\% of students stated in an open-ended question that they had the desire to practice thinking in new ways. One student stated, "I thought the very end -- when we were told we had put restrictions on ourselves, and that is why we didn't succeed as well as we could have -- was a bittersweet moment. I felt bad about not doing as well as I could have, but I also decided that I would use that 'sting' to remember the lesson that was being taught." Another exclaimed, "I've already started brainstorming boundaries that I put on myself like, how to get a job, how to be a good student, or the way that you should apply to graduate school. I want to constantly challenge the status quo of $\mathrm{HOW}$ we do things in order to look for ways to do it better or differently." This finding is also supported by anecdotal evidence of student thinking and behavior throughout the remaining weeks of the course. Let this be a fair warning to all instructors: it is very common for students to get "creative" or attempt to challenge unstated "rules" on assignments that follow this activity, although they generally ask for permission to do so. It may be a bit bothersome at times, but overall, it is exciting to see the students apply the principles and it frequently provides opportunities for continued learning.

Finally, $87 \%$ of respondents described positive experiences with the activity, $3 \%$ portrayed a negative experience, and the remaining $10 \%$ were neutral. Further, $95 \%$ of student respondents recommended that this activity continue to be used in future entrepreneurship and strategy classes. One MBA student wrote, "I liked the creativity of the activity. I think it was an excellent way to drive the points home that we have been discussing in class. I got way more out of the activity than I think I could have from reading in a book or listening to a lecture." Overall, students frequently describe this activity as an enjoyable and engaging opportunity to learn about their thinking styles and the potential barriers to creativity.

\section{Conclusion}

Entrepreneurship entails the discovery, evaluation, and exploitation of opportunities to create new and valuable products or services (Shane \& Venkataraman, 2000). It is critical that instructors create experiences that help students to recognize their own thinking styles and understand the implications of limited mental models ( $\mathrm{Ji}$ Hee \& Fish, 2010). The trading card exercise presented in this paper is one such exercise. It should be part of a larger effort to teach creativity and innovative thinking over a number of class periods. Students may learn the dangers of static mental models from the exercise but will need further training and practice with specific methods of breaking down barriers to creativity. An effort to expose students to experiential exercises that promote linear and non-linear thinking will benefit them as they embark in the very exciting world of entrepreneurism, whether in their own ventures or in a corporate environment.

\section{References}

Alvarez, S. A. \& Busenitz, L. W. (2001). The Entrepreneurship of Resource-based Theory. Journal of Management 27(6): 755.

Brock, S. A. (2010). Measuring the Importance of Precursor Steps to Transformative Learning. Adult Education Quarterly, 60(2), 122-142.

Chandler, G. N., DeTienne, D. R., McKelvie, A., Mumford, T. (2011). Causation and Effectuation 
Processes: A Validation Study. Journal of Business Venturing 26, 375-390.

Chang, C. M. (2008). Engaging the Creative Minds: the ENGAGE Model. International Journal of Innovation and Technology Management , 5(1), 149-165.

Goel, L., Johnson, N., Junglas, I., \& Ives, B. (2010). Situated Learning: Conceptualization and Measurement. Decision Sciences Journal of Innovative Education 8(1), 215-240.

Groves, K. S., Vance, C. M., Choi, D. Y., \& Mendez, J. L. (2008). An Examination of the Nonlinear Thinking Style Profile Stereotype of Successful Entrepreneurs. Journal of Enterprising Culture, 16(2), 133-159.

Holtom, B. C., Gagne, K. C., \& Tinsley, C. H. (2010). Using "Shocks and Rumors" to Teach Adaptive Thinking. Negotiation Journal, 26(1), 69-83.

Ji-Hee, K., \& Fish, L. (2010). From Nothing to Something: An Experiential Entrepreneurship Exercise. Decision Sciences Journal Of Innovative Education, 8(1), 241-255.

Johansson, F. (2006). The Medici Effect. Harvard Business School Press, Boston, MA.

Mezirow, J. (1994). Understanding Transformation Theory. Adult Education Quarterly, 46, 22-32.

Neck, H. M., \& Greene, P. G. (2011). Enterpreneurship Education: Known Worlds and New Frontiers. Journal of Small Business Management, 49(1), 55-70.

Sarasvathy, S. D. (2001). Casation and Effectuation: Toward a Theoretical Shift from Economic Enevitability to Entrepreneurial Contingency. Academy of Management Reveiew, 26(2), 243-263.

Sarasvathy, S. D. (2004). What makes entrepreneurs entrepreneurial? Batten Briefings.

Shane, S., \& Venkataraman, S. (2000). The Promise of Entrepreneurship as a Field of Research. Academy of Management Review 25(1), 217-226.

Terwiesch, C. \& Ulrich, K. T. (2009). Innovation Tournaments. Harvard Business Press, Boston, MA.

Vance, C., Groves, K., Paik, Y., \& Kindler, H. (2007). Understanding and Measuring Linear-Nonlinear
Thinking Style for Enhanced Management Education and Professional Practice. Academy of Management Learning \& Education , 6, 167-185.

\section{Acknowledgements}

Thanks to Rebecca Drebin for her contribution to an earlier version of this article. She was an outstanding teaching and research assistant who was instrumental in helping me to translate this classroom exercise into written form.

\section{More ideas}

College business professors looking for more ideas to enrich the classroom experience can find them here (https://eiexchange.com/eix-in-class) .

Additional Search Terms: entrepreneurship courses, teaching ideas, teaching resources, classroom ideas, entrepreneurship classes, business schools, business school classes, entrepreneurship students, professors 


\section{Appendix I: Sample Trading Cards}




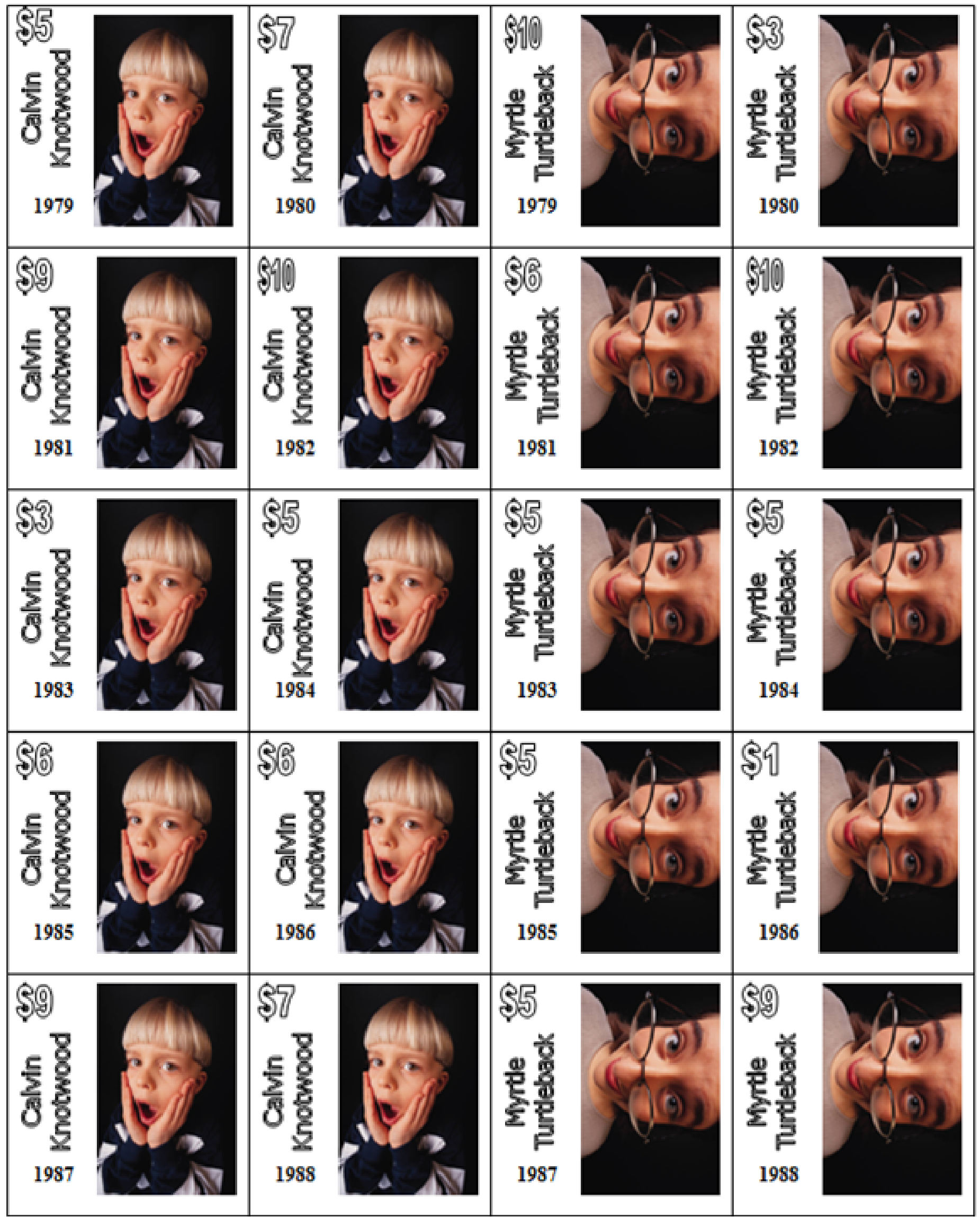


Appendix II: Spreadsheet of Trading Card Values

\begin{tabular}{|c|c|c|c|c|c|c|c|c|c|c|c|c|c|}
\hline & $\begin{array}{c}\text { Gabby } \\
\text { Wanamaker }\end{array}$ & $\begin{array}{c}\text { Zoe } \\
\text { Lickliter }\end{array}$ & $\begin{array}{l}\text { Sophia } \\
\text { Belen }\end{array}$ & $\begin{array}{l}\text { Zelda } \\
\text { Orphus }\end{array}$ & $\begin{array}{c}\text { Calvin } \\
\text { Knotwood }\end{array}$ & $\begin{array}{l}\text { Myrtle Tur- } \\
\text { tleback }\end{array}$ & $\begin{array}{c}\text { Arthur } \\
\text { Amadama }\end{array}$ & $\begin{array}{c}\text { Kento } \\
\text { Fonzarelli }\end{array}$ & $\begin{array}{c}\text { Sandy } \\
\text { Swinedell }\end{array}$ & $\begin{array}{c}\text { Ruth } \\
\text { Wiseloft }\end{array}$ & Total & $\begin{array}{l}\text { Bonus } \\
\text { for set }\end{array}$ & $\begin{array}{c}\text { Grand } \\
\text { Total }\end{array}$ \\
\hline 1979 & 510 & $\$ 2$ & 5.5 & $\$ 1$ & $\$ 5$ & $\$ 10$ & $\$ 5$ & $\$ 5$ & $\$ 6$ & $\$ 6$ & $\$ 55$ & $\$ 55$ & $\$ 110$ \\
\hline 1980 & $\$ 9$ & $\$ 4$ & 56 & $\$ 8$ & $\$ 7$ & $\$ 3$ & $\$ 2$ & $\$ 3$ & $\$ 10$ & $\$ 7$ & $\$ 59$ & $\$ 51$ & $\$ 110$ \\
\hline 1981 & $\$ 9$ & $\$ 7$ & 59 & $\$ 10$ & $\$ 9$ & 56 & $\$ 4$ & $\$ 1$ & $\$ 4$ & $\$ 7$ & $\$ 66$ & $\$ 39$ & $\$ 105$ \\
\hline 1982 & 510 & $\$ 1$ & $\$ 3$ & $\$ 8$ & $\$ 10$ & $\$ 10$ & $\$ 5$ & $\$ 4$ & $\$ 5$ & $\$ 3$ & $\$ 59$ & $\$ 46$ & 5105 \\
\hline 1983 & $\$ 3$ & $\$ 2$ & 58 & $\$ 8$ & $\$ 3$ & 55 & $\$ 5$ & $\$ 6$ & $\$ 8$ & $\$ 10$ & $\$ 58$ & $\$ 42$ & 5100 \\
\hline 1984 & $\$ 9$ & $\$ 9$ & S6 & $\$ 6$ & $\$ 5$ & 55 & $\$ 6$ & 59 & $\$ 4$ & $\$ 1$ & $\$ 60$ & $\$ 40$ & $\$ 100$ \\
\hline 1985 & $\$ 5$ & $\$ 8$ & $\$ 10$ & $\$ 4$ & $\$ 6$ & 55 & $\$ 4$ & $\$ 3$ & $\$ 6$ & $\$ 5$ & $\$ 56$ & $\$ 39$ & $\$ 95$ \\
\hline 1986 & $\$ 2$ & $\$ 6$ & 5.5 & $\$ 7$ & $\$ 6$ & $\$ 1$ & $\$ 8$ & $\$ 2$ & $\$ .5$ & $\$ 5$ & $\$ 4^{7}$ & $\$ 48$ & $\$ 95$ \\
\hline 1987 & $\$ 8$ & $\$ 7$ & 56 & $\$ 9$ & $\$ 9$ & 55 & $\$ 3$ & $\$ 5$ & $\$ 1$ & $\$ 7$ & $\$ 60$ & $\$ 30$ & $\$ 90$ \\
\hline 1988 & $\$ 9$ & $\$ 6$ & $\$ 2$ & $\$ 4$ & $\$ 7$ & 59 & $\$ 9$ & $\$ 1$ & $\$ 9$ & $\$ 1$ & $\$ 5^{7}$ & $\$ 33$ & $\$ 90$ \\
\hline Total & $\$ 74$ & $\$ 52$ & 560 & $\$ 65$ & $\$ 67$ & 559 & $\$ 51$ & $\$ 39$ & 558 & $\$ 52$ & & & \\
\hline $\begin{array}{l}\text { Bonus } \\
\text { for set }\end{array}$ & $\$ 16$ & $\$ 38$ & $\$ 35$ & $\$ 30$ & $\$ 33$ & $\$ 41$ & $\$ 54$ & $\$ 66$ & $\$ 52$ & $\$ 58$ & & & \\
\hline $\begin{array}{c}\text { Grand } \\
\text { Total }\end{array}$ & $\$ 90$ & $\$ 90$ & $\$ 95$ & $\$ 95$ & $\$ 100$ & $\$ 100$ & $\$ 105$ & $\$ 105$ & $\$ 110$ & $\$ 110$ & & & \\
\hline
\end{tabular}

